\title{
Beriberi and Pyruvic Acid
}

By

\section{Akira Sato \\ (佐 藤 彰)}

(From the Department of Pediatrics, Faculty of Medicine, the Tohoku University, Sendai. Director: Prof. A. Sato)

(Received for publication, November 16, 1951)

More than 100 papers $^{13}$ have been published from our Clinic and Laboratory since 1930 concerning beriberi esp. thiamine deficiency of lactants and infants. Those who have seen these papers must have wondered whether we were even aware of the world athiaminosis literature which had been centering on pyruvic acid, while our treatise must seem to be centering upon methyl gloyxal-a metabolite which modern theory of avitaminosis has abandoned almost utterly, so that if recent literature (books) ${ }^{2)}$ on athiaminosis does ever mention methygloyoxal, it is almost from our sources.

The only reference from our Laboratory that ever treated pyruvic acid is Ts. Arakawa's ${ }^{3)}$ treatise. Even then, I stated at the end of his treatise to the effect that this colorimetric result ought to be checked by strict chemical determination.

Why this reservation? Why such an apparent defiance at the current pyruvate theory as above mentioned?

Soon after our human milk study was started, we began to have a firm be. lief in "methyl glyoxal" as beriberi poison")(1934). Of course we had not ignored the world wide opinion of pyruvate as the poison, and we made preliminary animal experimentaion in the same way as in the case of glyoxals. But such a striking deleterious effect upon animals' health was not observed. So all the rabbits used were killed, but their hearts were not found enlarged either. Later, Wako ${ }^{6}$ in our Laboratory tried a similar experiment with freshly prepared pyruvic acid and came to the same conclusion.

\section{References}

1) Cf. the Reports of the Peroxidase Reaction, Tohoku J. Exp. Med., since 1930 up to date. 2) Williams R. R., and Spies, T. D., Vitamin $B_{1}$ and Its Use in Medicine, 1940, pp. 363-364, Macmillan, New York. Bicknell F., and Prescott, F., The Vitamins in Medicine, 1948, 2nd Edit, p. 193, Heinemann, London. MaCollum, E. V., Orent Keiles, E., and Day, H. G., The Newer Knowledge of Nutrition, 1940, 5th Edit, p. 465, Macmillan Co, New York. 3) Arakawa, Ts., Tohoku J. Exp. Med., 1950, 53, 171. 4) Takamatsu A., and Sato, A., ibid,, 1934, 28, 506. 5) Sato, A., (The Most Typical Symptom of Infantile Beriberi), ibid., this volume, p. 6. 6) Wako. H., (Pyruvic Acid and Heart Enlarging; and Acetaldehyde, Preliminary Report,) ibid., this volume, p. 28. 